\title{
Transit Station Congestion Index Research Based on Pedestrian Simulation and Gray Clustering Evaluation
}

\author{
Shu-wei Wang, Li-shan Sun, Jian Rong, and Zi-fan Yang \\ Key Laboratory of Transportation Engineering, Beijing University of Technology, Beijing 100124, China \\ Correspondence should be addressed to Li-shan Sun; lssun@bjut.edu.cn
}

Received 2 September 2013; Accepted 13 November 2013

Academic Editor: Geert Wets

Copyright (C) 2013 Shu-wei Wang et al. This is an open access article distributed under the Creative Commons Attribution License, which permits unrestricted use, distribution, and reproduction in any medium, provided the original work is properly cited.

\begin{abstract}
A congestion phenomenon in a transit station could lead to low transfer efficiency as well as a hidden danger. Effective management of congestion phenomenon shall help to reduce the efficiency decline and danger risk. However, due to the difficulty in acquiring microcosmic pedestrian density, existing researches lack quantitative indicators to reflect congestion degree. This paper aims to solve this problem. Firstly, platform, stair, transfer tunnel, auto fare collection (AFC) machine, and security check machine were chosen as key traffic facilities through large amounts of field investigation. Key facilities could be used to reflect the passenger density of a whole station. Secondly, the pedestrian density change law of each key traffic facility was analyzed using pedestrian simulation, and the load degree calculating method of each facility was defined, respectively, afterwards. Taking pedestrian density as basic data and gray clustering evaluation as algorithm, an index called Transit Station Congestion Index (TSCI) was constructed to reflect the congestion degree of transit stations. Finally, an evaluation demonstration was carried out with five typical transit transfer stations in Beijing, and the evaluation results show that TSCI can objectively reflect the congestion degree of transit stations.
\end{abstract}

\section{Introduction}

Urban rail transit is one of the most important public transport modes. Transit stations, especially transfer stations, suffer from large passenger flow pressure during peak hours, and congestion phenomenon often occurs. It is easy to understand that congestion phenomenon in transit transfer stations could lead to low transfer efficiency, as well as hidden danger of passenger security. Thus, effective management of congestion phenomenon shall help to reduce the efficiency decline and danger risk. However, due to the difficulty in acquiring microcosmic pedestrian density, most of the existing researches lack quantitative indicators to reflect congestion degree. In order to quantify congestion degree, this paper puts forward a concept of Transit Station Congestion Index (TSCI) according to Global Port Congestion Index (GPCI). GPCI is published weekly to detailedly and timely reflect the retention situation of coal, ore, and other dry bulk fleets in major ports around the world, for the purpose of analyzing the influence of port congestion on the supply and demand of dry bulk market. Up to now, GPCI has covered 80 major ports from different countries, including Australia, Brazil, China, India, and South Africa. Just like GPCI, TSCI could help to achieve effective control of transit station congestion phenomenon, which would help to reduce the efficiency decline and danger risk.

Previous researches mainly focus on the qualitative analysis of traffic facility pedestrian flow characteristics, which can be outlined as below. Older [1] found that the pedestrian flow characteristics of different traffic facilities vary a lot. Helbing [2] found that the geometric boundary of traffic facilities can affect pedestrian space and facility capacity. Fruin [3] put forward a traffic facility level of service evaluation and classification theory based on the pedestrian density, through the analysis of stair, platform, and traffic facilities' pedestrian density characteristic. Based on the research of Fruin, the United States Transportation Research Board [4] proposed a pavement level of service classification standard in the Highway Capacity Manual (HCM). Seneviratne and Morrall [5] and Tanaboriboon et al. [6] found that pedestrian traffic 
characteristics of different countries vary greatly and pointed out that all traffic facility researches should be combined with local pedestrian characteristic.

In recent years, some researchers began to study the microbehavior law of public transport pedestrian. Hoogendoorn et al. proposed a NOMAD model to describe pedestrian behavior and a SimPed model to describe pedestrian flow characteristics under the influence of the interacting of different public transport means [7-10]. Kitazawa and Batty modified the profit condition of shortest path choices under the influence of uncertain factors and conducted a research of the pedestrian movement path with a genetic algorithm [11]. Schelhorn et al. constructed a STREETS model through the analysis of individual characteristics and attraction points in pedestrian movement and described the movement situation of urban streets using the Agent model [12]. Desyllas and Duxbury analyzed the influence of different street patterns on pedestrian attraction through the method of modeling city morphology and quantified the influence of city infrastructure on pedestrian flow volume with the visual analysis method [13]. Kwon et al. researched in the influence of narrow city streets on the pedestrians detour obstacles behavior [14]. Hine evaluated the influence of traffic environment on behavior and safety perception of pedestrians [15]. Peter Thompson classified and described the pedestrian behavior under building evacuation circumstances and pointed out that pedestrian behavior will be influenced by corridor width and mentation [16]. Gipps and Marksjö [17] developed a cellular automaton model to analyze the pedestrian motion law in a continuous space. Hoofendoorn [18] conducted further research on pedestrian simulation based on the hypothesis of individual utility maximization and proposed a pedestrian route choice and activity planning model.

In general, most of the current researches focus on individual problems and lack quantitative indicators to reflect transit station congestion degree. This paper aims to solve the above problems and an index called Transit Station Congestion Index (TSCI) was constructed to reflect the congestion degree of transit stations. Firstly, in order to quantify congestion degree, the density change law of key traffic facilities in a transit station was analyzed through pedestrian simulation. Secondly, the load degree calculating method of each kind of key traffic facility was defined based on its pedestrian density change law. Thirdly, taking pedestrian density as basic data and gray clustering evaluation as algorithm, an index called Transit Station Congestion Index (TSCI) was constructed to reflect the congestion degree of transit stations. Finally, the practicability of TSCI was verified with an evaluation demonstration of five typical transit transfer stations in Beijing.

This paper consists of six parts: the first part summarized the existing researches related to transit station congestion degree; the second part determined the key traffic facilities in a transit transfer station and conducted pedestrian simulation to analyze the pedestrian density change law of each key traffic facility; the third part proposed the load degree calculating method of each key traffic facility on the basis of its pedestrian density change law; the fourth part constructed an index called Transit Station Congestion Index (TSCI) to reflect
TABLE 1: Transfer form and transfer line of typical stations.

\begin{tabular}{lcc}
\hline Transit station & Transfer lines & Transfer form \\
\hline SHD & Line Batong and Line 1 & Station hall transfer \\
FXM & Line 1 and Line 2 & Tunnel transfer \\
GM & Line 1 and Line 10 & Tunnel transfer \\
HXXJNK & Line 5 and Line 10 & Station hall transfer \\
SJZ & Line 5 and Line & Platform transfer \\
\hline
\end{tabular}

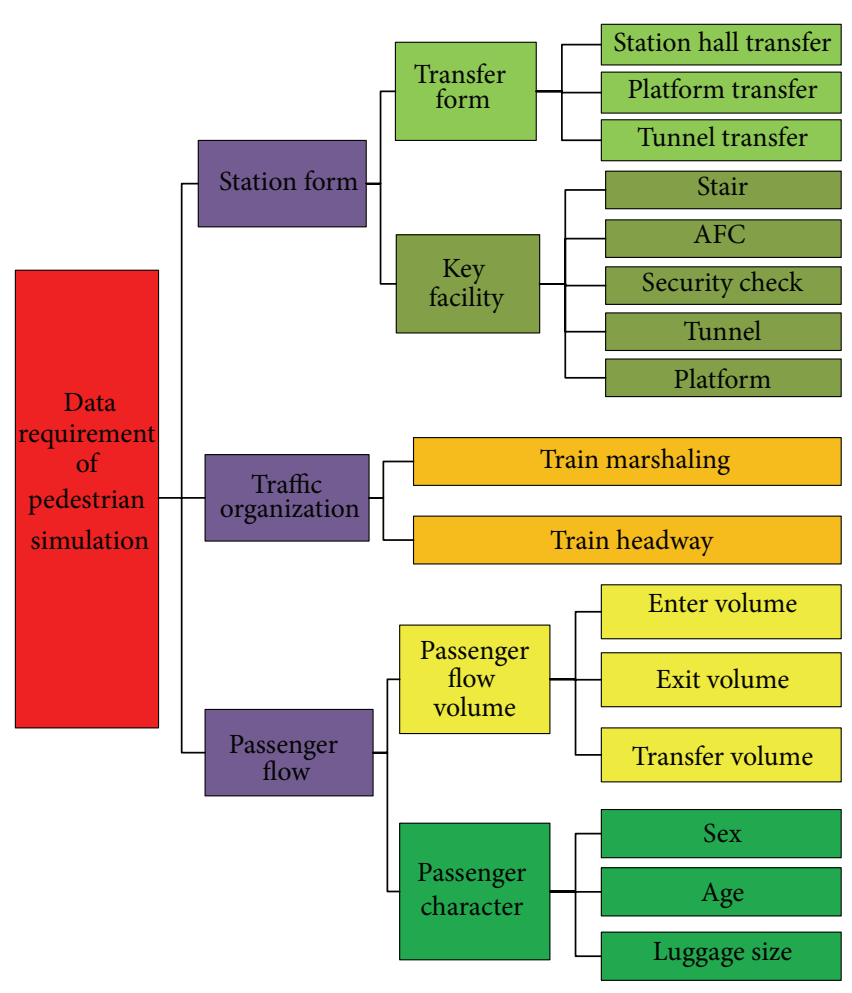

FIGURE 1: Factors affecting transit station congestion degree.

the congestion degree of transit stations by taking pedestrian density as basic data and gray clustering evaluation as algorithm; the fifth part carried out an evaluation demonstration of five typical transit transfer stations in Beijing; the last part is conclusions of this paper.

\section{Pedestrian Simulation}

2.1. Field Investigation. The congestion degree of transit stations is typically affected by three factors: station form, traffic organization, and passenger flow; these three types of data are also the data requirements of pedestrian simulation, as shown in Figure 1.

Considering both the diversity of transfer form and the severity of congestion, SHD station, FXM station, GM station, HXXJNK station, and SJZ station were chosen as typical stations to conduct research; their transfer form and transfer lines are shown in Table 1.

In order to conduct pedestrian simulation, field investigation of selected transit stations needed to be carried out. 


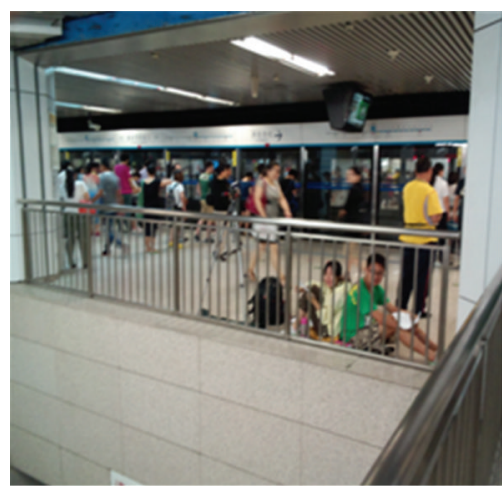

(a)

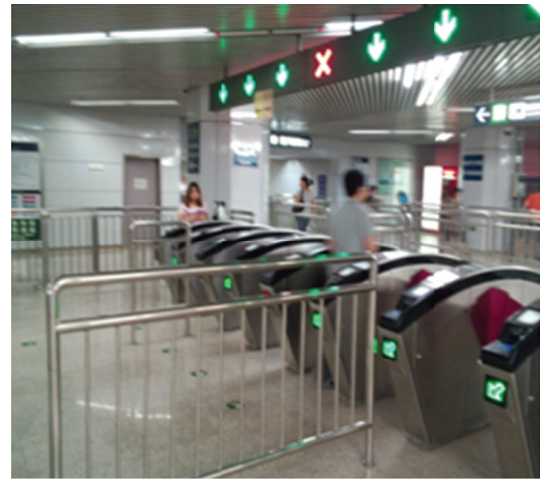

(b)

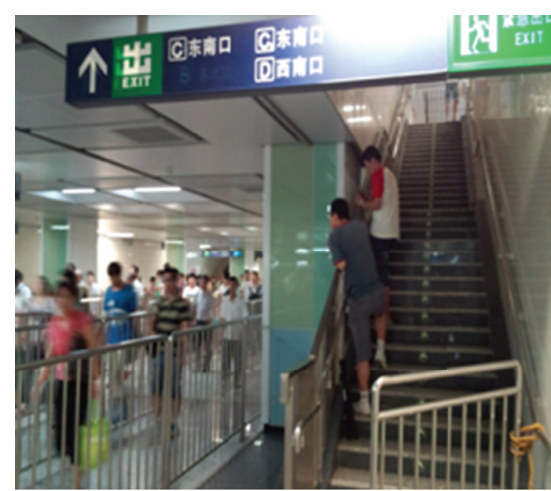

(c)

FIgURE 2: Part of the positions of passenger flow investigation.

TABLE 2: Proportion of different types of passengers.

\begin{tabular}{lcc}
\hline Transit station & No luggage ratio & Small luggage ratio \\
\hline SHD & $90 \%$ & $10 \%$ \\
GM & $85 \%$ & $10 \%$ \\
HXXJNK & $85 \%$ & $15 \%$ \\
FXM & $80 \%$ & $20 \%$ \\
SJZ & $80 \%$ & $20 \%$ \\
\hline
\end{tabular}

The investigation time was chosen as the morning peak period (07:00-09:00) of July 2, 4, and 6, 2012. As mentioned in Figure 1, the survey content included station form, traffic organization, and passenger flow, where the passenger flow investigation was conducted by manual counting, as shown in Figure 2.

2.2. Simulation Model Construction. There is plenty of pedestrian simulation software to choose from, including LEGION, STEPS, BUILDINGEXDOUS, MYRIAD, PAXPORT, and SIMULEX. Each of them has its speciality and should be selected according to research purpose. Research purpose of this paper is to analyze the pedestrian density change law of different facilities in a transit station of Beijing; therefore, considering LEGION has a pedestrian motion model which was established based on the characteristic of Beijing citizens and at the same time has a well-designed simulation model for each kind of traffic facilities in a transit transfer station, it was eventually chosen. The construction procedure of pedestrian model includes the following: draw the CAD simulation map based on station form, import simulation map into LEGION and add transfer facilities, set traffic organization scheme, and finally add passenger flow information. Choose "Chinese Commuters" as pedestrian type and the passenger character is shown in Table 2.

Part of the other key parameters includes the following.

(i) Escalator: $0.65-0.75 \mathrm{M} / \mathrm{s}$; tilt angle $30-45^{\circ}$.

(ii) AFC: delay time as $2 \mathrm{~s}$.

(iii) Security check: reception capacity as 3-5 persons at a time; delay time $2.25 \mathrm{~s}$.

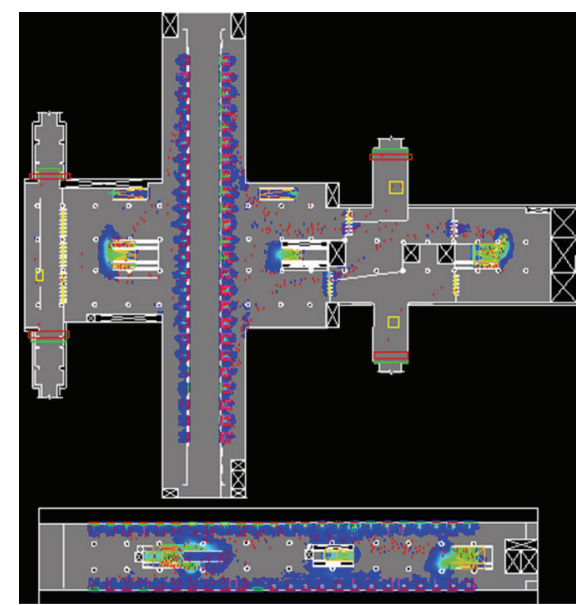

FIGURE 3: Simulation model of HXXJNK station.

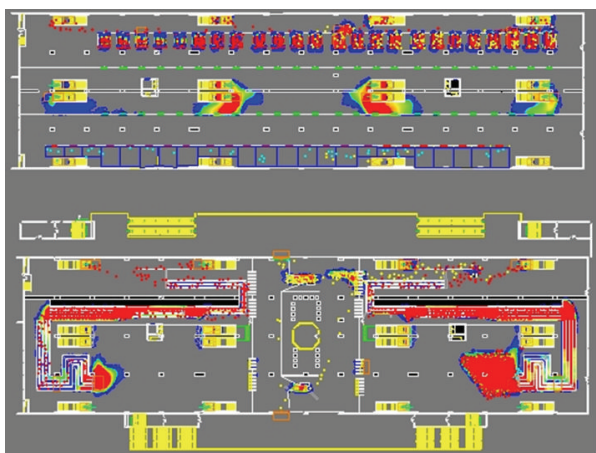

FIGURE 4: Simulation model of SHD station.

The complete simulation models are shown as Figures 3, $4,5,6$, and 7 .

2.3. Key Traffic Facility Pedestrian Density Analysis. Transit stations are usually too complicate, and it is difficult to analyze the pedestrian density of all areas. However, there are typical traffic facilities in every transit station, whose capacity usually 


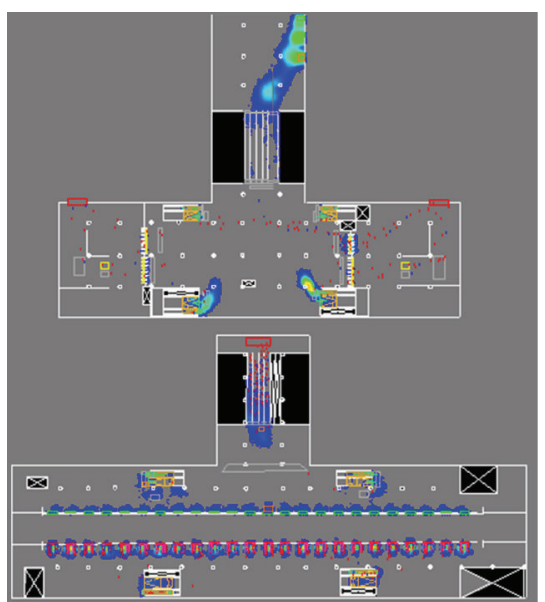

FIGURE 5: Simulation model of SJZ station.

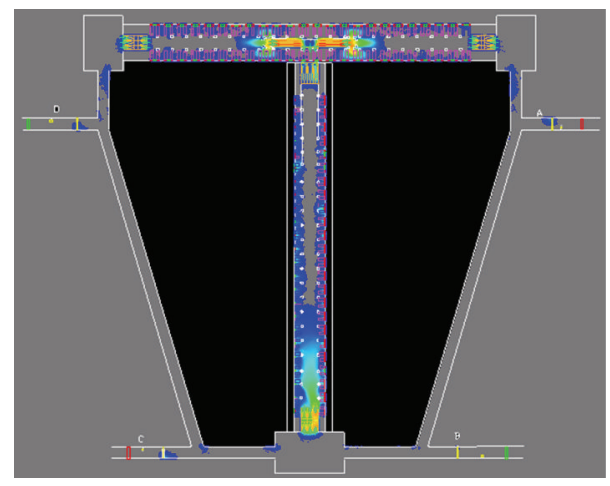

FIGURE 6: Simulation model of FXM station.

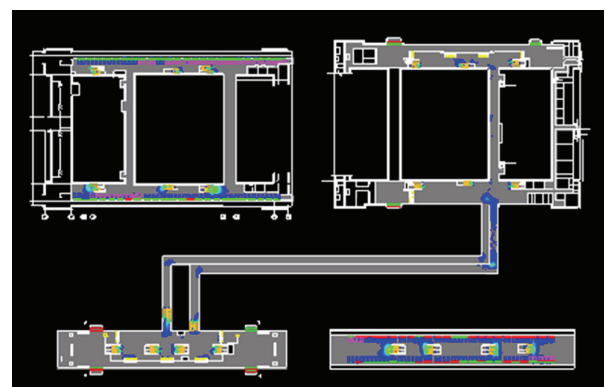

FIGURE 7: Simulation model of GM station.

makes them bottlenecks of passenger flow lines, such as security check, AFC, stair, tunnel, ticket office, and platform. Field investigation shows that platform, stair, tunnel, security and AFC are traffic facilities with the highest utilization rate and could reflect the pedestrian density characteristics of the whole station. Therefore, choose these five facilities as key traffic facilities in a transit station and analyze their pedestrian density change law. The pedestrian density data of the objects of study per 0.6 second during simulation period are shown as Figures 8, 9, 10, 11, and 12 .

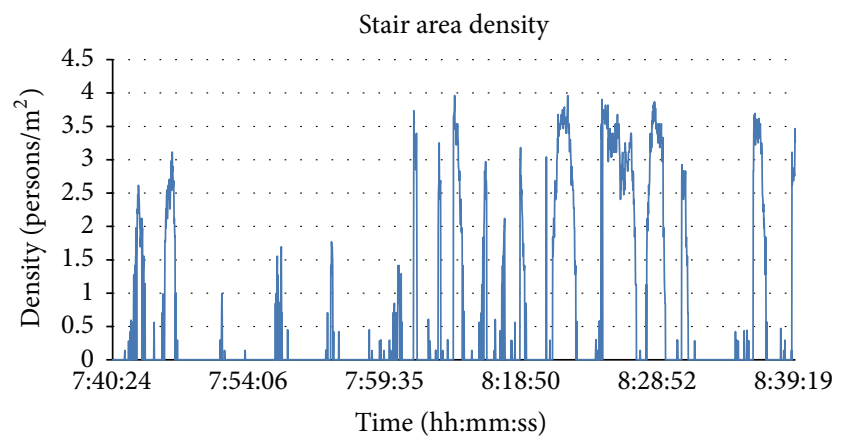

FIGURE 8: Average pedestrian density of stair area every 0.6 second.

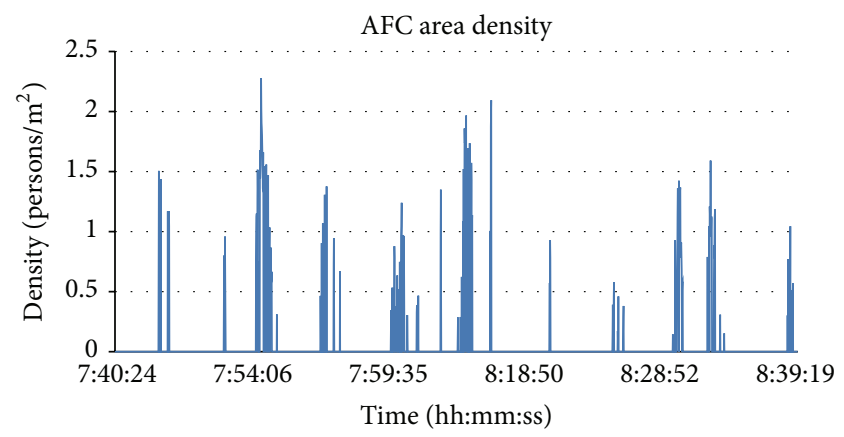

FIGURE 9: Average pedestrian density of AFC area every 0.6 second.

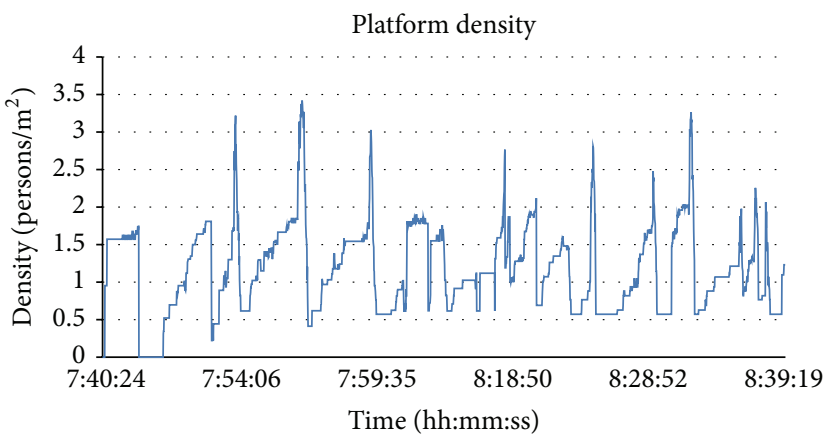

FIGURE 10: Average pedestrian density of platform area every 0.6 second.

\section{Calculating Method of Key Traffic Facility Load Degree}

The pedestrian density of key traffic facilities changes periodically, repeating the process from passenger arriving to dissipation. In order to get the density variation range of each facility, define the load degree when pedestrian density is zero as minimum load and maximum load when pedestrian density reaches the summit. Given the fact that the pedestrian change laws of each type of traffic facility vary from each other, their load degree calculating standards should be different. Based on the above analysis, remove the data where pedestrian density is zero, and rank the rest in an ascending order. Ranking result shows that the passenger density data 


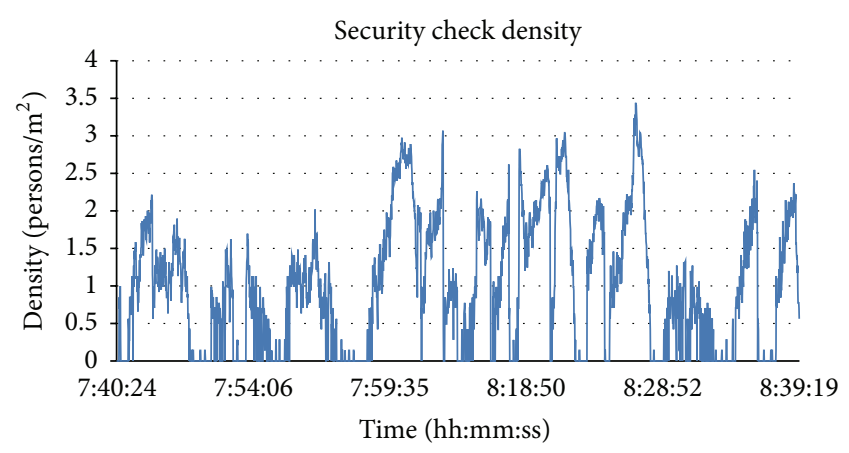

FIGURE 11: Average pedestrian density of security check area every 0.6 second.

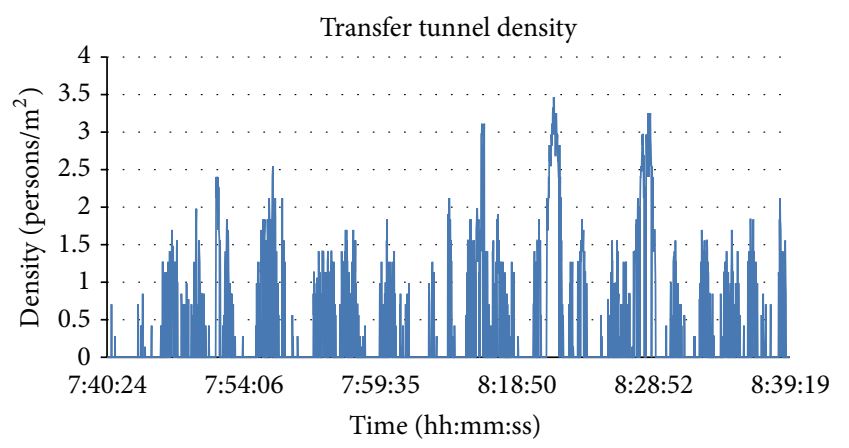

FIGURE 12: Average pedestrian density of transfer tunnel every 0.6 second.

of each key traffic facility in a typical period obeys a normal distribution. As we all know, normal distribution has two special points on the midline symmetry, which are called $15 \%$ fractile and $85 \%$ fractile; the pedestrian density growth rate between these two points is significantly higher than that of other regions. Take the pedestrian density at the $15 \%$ fractile, $50 \%$ fractile, and $85 \%$ fractile of each type of traffic facility as the load degree calculating standard. Therefore, load degree is divided into four categories, as shown in Table 3, and the unit is passengers per square meter.

\section{Grey Clustering Evaluation Model of Transit Station Congestion Index}

The passenger flow status in a transit station is rather complex and can be treated as a system in which part of the information is not clear; therefore, chose the pedestrian density of platform, stair, AFC, security check, and tunnel as basic data and grey clustering model as evaluation method to construct a hybrid index, and name this index "transit station congestion index." The concept of grey system is proposed by Chinese professor Julong Deng and is designed to analyze systems in which part of the information is not clear; in a grey system, all the random variables and stochastic processes are considered as grey variables and grey processes [16]. Grey clustering method is a method based on the establishment of whitenization weight function; it clusters objects according to
TABLE 3: Density value of traffic facility load degree.

\begin{tabular}{lccccc}
\hline Load degree & \multicolumn{5}{c}{ Facility } \\
& $\begin{array}{c}\text { Security } \\
\text { check }\end{array}$ & AFC & Tunnel & Stair & Platform \\
\hline I & 0.148 & 0.713 & 0.612 & 0.982 & 0.424 \\
II & 0.349 & 1.466 & 1.061 & 2.617 & 1.056 \\
III & 0.819 & 1.956 & 1.804 & 3.607 & 2.321 \\
IV & 2.915 & 3.487 & 3.961 & 5.006 & 4.867 \\
\hline
\end{tabular}

the whitenization weight function of different indexes, summarizes these indexes into grey categories, and determines which grey category the clustering object belongs to. According to the load degree classification standard in Table 3 , establish the whitenization weight function of each type of traffic facility:

$$
\begin{gathered}
f_{j}^{1}\left(x_{i j}\right) \begin{cases}1, & x_{i j}=S_{j 1}, \\
\frac{x_{i j}-S_{j 2}}{S_{j 1}-S_{j 2}}, & S_{j 1}<x_{i j}<S_{j 2}, \\
0, & x_{i j} \geq S_{j 2},\end{cases} \\
f_{j}^{2}\left(x_{i j}\right) \begin{cases}1, & x_{i j}=S_{j 2}, \\
\frac{x_{i j}-S_{j 1}}{S_{j 2}-S_{j 1}}, & S_{j 1}<x_{i j}<S_{j 2}, \\
\frac{x_{i j}-S_{j 3}}{S_{j 2}-S_{j 3}}, & S_{j 2}<x_{i j}<S_{j 3}, \\
0, & x_{i j} \leq S_{j 1} \text { or } x_{i j} \geq S_{j 3},\end{cases} \\
f_{j}^{3}\left(x_{i j}\right) \begin{cases}\frac{1,}{x_{i j}-S_{j 2}}, & x_{i j}=S_{j 3}, \\
S_{j 3}-S_{j 2} & x_{i j}<S_{j 3}, \\
\frac{x_{i j}-S_{j 4}}{S_{j 3}-S_{j 4}}, & S_{j 3}<x_{i j}<S_{j 4}, \\
0, & x_{i j} \leq S_{j 2} \text { or } x_{i j} \geq S_{j 4},\end{cases} \\
f_{j}^{4}\left(x_{i j}\right) \begin{cases}1, & x_{i j} \geq S_{j 4}, \\
\frac{x_{i j}-S_{j 3}}{S_{j 4}-S_{j 3}}, & S_{j 3}<x_{i j} \leq S_{j 4}, \\
0, & x_{i j} \leq S_{j 3},\end{cases}
\end{gathered}
$$

where $f_{j}^{1}\left(x_{i j}\right), f_{j}^{2}\left(x_{i j}\right), f_{j}^{3}\left(x_{i j}\right)$, and $f_{j}^{4}\left(x_{i j}\right)$ are the whitenization weight functions of the four grey categories of facility $j$, $S_{j 1}, S_{j 2}, S_{j 3}$, and $S_{j 4}$ are the pedestrian density value of the corresponding I, II, III, and IV grey categories of facility $j$, and $x_{i j}$ is the pedestrian density of facility $j$ of transit station $i$.

The pedestrian density characteristics of different facilities vary from each other; if calculated directly, the evaluation 
TABLE 4: Dimensionless grey category value.

\begin{tabular}{lccccc}
\hline $\begin{array}{l}\text { Grey } \\
\text { category }\end{array}$ & $\begin{array}{c}\text { Security } \\
\text { check }\end{array}$ & AFC & Tunnel & Stair & Platform \\
\hline I & 0.051 & 0.248 & 0.213 & 0.341 & 0.147 \\
II & 0.053 & 0.224 & 0.162 & 0.400 & 0.161 \\
III & 0.078 & 0.186 & 0.172 & 0.343 & 0.221 \\
IV & 0.144 & 0.172 & 0.196 & 0.247 & 0.241 \\
\hline
\end{tabular}

TABLE 5: Clustering weight of each key traffic facility.

\begin{tabular}{lccccc}
\hline $\begin{array}{l}\text { Grey } \\
\text { category }\end{array}$ & $\begin{array}{c}\text { Security } \\
\text { check }\end{array}$ & AFC & Tunnel & Stair & Platform \\
\hline I & 0.51 & 0.11 & 0.12 & 0.08 & 0.18 \\
II & 0.49 & 0.12 & 0.16 & 0.07 & 0.16 \\
III & 0.41 & 0.17 & 0.19 & 0.09 & 0.14 \\
IV & 0.27 & 0.22 & 0.20 & 0.16 & 0.16 \\
\hline
\end{tabular}

function of facilities with lower density will be smaller; therefore, conduct a dimensionless treatment to the grey values via the following formula (the results are in Table 4):

$$
y_{j k}=\frac{S_{j k}}{\sum_{1}^{4} S_{j k}} .
$$

Facilities with larger grey category value are more likely to encounter high density and should be given a relatively smaller weight. Therefore, apply the inverse weighting method to determine the clustering weight of each key traffic facility via the following Formula (3) and the results are shown in Table 5:

$$
\eta_{j k}=\frac{1 / y_{j k}}{\sum_{j=1}^{m}\left(1 / y_{j k}\right)},
$$

where $\eta_{j k}$ is the clustering weight of grey category $k$ of facility $j ; y_{j k}$ is the dimensionless value of grey category $k$ of facility $j$.

Calculate the clustering evaluation value of transit station $i$ in grey category $t$ via the following Formula:

$$
\sigma_{i}^{k}=\sum_{j=1}^{m} f_{j}^{k}\left(x_{i j}\right) \eta_{j k} .
$$

Therefore, the grey clustering evaluation sequence of transit station $i$ is $\sigma_{i}=\left\{\sigma_{i 1}, \sigma_{i 2}, \sigma_{i 3}, \sigma_{i 4}\right\}$, and the grey category it belongs to should be $\sigma_{i}^{*}=\max \left\{\sigma_{i 1}, \sigma_{i 2}, \sigma_{i 3}, \sigma_{i 4}\right\}$. Grey category reflects the congestion degree of a transit station, and the higher the grey category, the higher the congestion degree.

\section{Evaluation Demonstration}

Record the pedestrian density (including zero) of the five typical transit stations during peak hour (07:30-08:30), rank
TABLE 6: Initial index value of evaluation demonstration.

\begin{tabular}{lccccc}
\hline $\begin{array}{l}\text { Transit } \\
\text { station }\end{array}$ & $\begin{array}{c}\text { Security } \\
\text { check }\end{array}$ & AFC & Tunnel & Stair & Platform \\
\hline SHD & 2.14 & 1.963 & 1.34 & 3.287 & 4.409 \\
GM & 0.594 & 1.98 & 1.839 & 3.614 & 1.923 \\
HXXJNK & 0.31 & 1.553 & 2.192 & 3.395 & 1.813 \\
FXM & 0.304 & 2.012 & 1.358 & 3.932 & 1.641 \\
SJZ & 0.565 & 1.85 & 2.193 & 2.622 & 1.819 \\
\hline
\end{tabular}

TABLE 7: Initial index value of evaluation demonstration.

\begin{tabular}{lccccc}
\hline Results & \multicolumn{5}{c}{ Facility } \\
& SHD & GM & HXXJNK & FXM & SJZ \\
\hline I & 0.00 & 0.00 & 0.10 & 0.11 & 0.00 \\
II & 0.12 & 0.29 & 0.57 & 0.57 & 0.42 \\
III & 0.48 & 0.75 & 0.34 & 0.38 & 0.56 \\
IV & 0.30 & 0.01 & 0.04 & 0.04 & 0.04 \\
Grey category & III & III & II & II & III \\
\hline
\end{tabular}

them in ascending order, and take the $85 \%$ fractile value as the initial index value, as shown in Table 6, and the unit is passengers per square meter.

Calculate the clustering evaluation value of each station via (4), and the results are shown in Table 7.

As shown in Table 7, SHD,GM, and SJZ stations belong to grey category III, and their congestion degree is relatively high; HXXJNK and GXM stations belong to grey category II, and the congestion degree is relatively low.

Compare the evaluation results with simulation results, and verify the objectivity of the proposed TSCI evaluation method. Simulated average pedestrian density distribution is shown in Figures 13 and 14, where different colors represent different density values, as shown in Figure 15.

Pedestrian density simulation results show that most areas of GM and SJZ stations stay between $3.59 \mathrm{P} / \mathrm{m}^{2}$ and $5.38 \mathrm{P} / \mathrm{m}^{2}$, few areas above $5.38 \mathrm{P} / \mathrm{m}^{2}$, and the congestion degree is relatively high; most areas of HXXJNK and FXM stations stay between $1.08 \mathrm{P} / \mathrm{m}^{2}$ and $1.54 \mathrm{P} / \mathrm{m}^{2}$, few areas between $3.59 \mathrm{P} / \mathrm{m}^{2}$ and $5.38 \mathrm{P} / \mathrm{m}^{2}$, very few areas above $5.38 \mathrm{P} / \mathrm{m}^{2}$, and the congestion degree is relatively low.

According to the above analysis, simulation results and evaluation conclusion are consistent, which means the proposed evaluation method of TSCI is feasible.

\section{Conclusion}

Through the pedestrian density analysis conducted in this paper, the load degree calculating method of each key traffic facility was proposed, which could help to lay a basis for the quantitative analysis of transit station passenger flow. Additionally, the construction of Transit Station Congestion Index (TSCI) is a beneficial attempt to reflect the congestion degree of transit stations, and the evaluation demonstration 

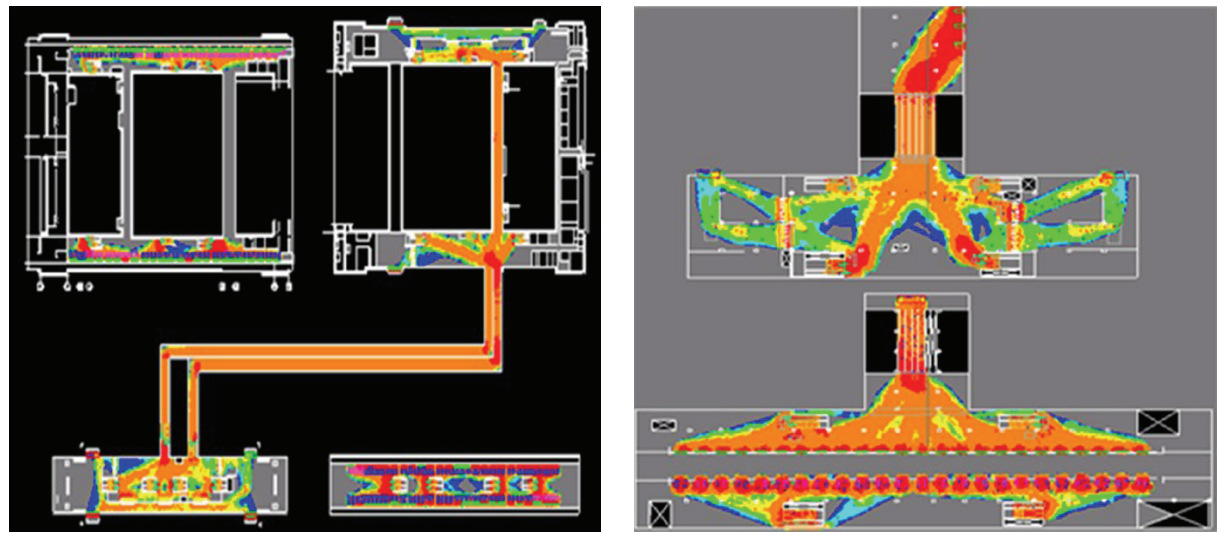

FIGURE 13: Simulated average pedestrian density distribution of GM and SJZ stations (TSCI = 3).
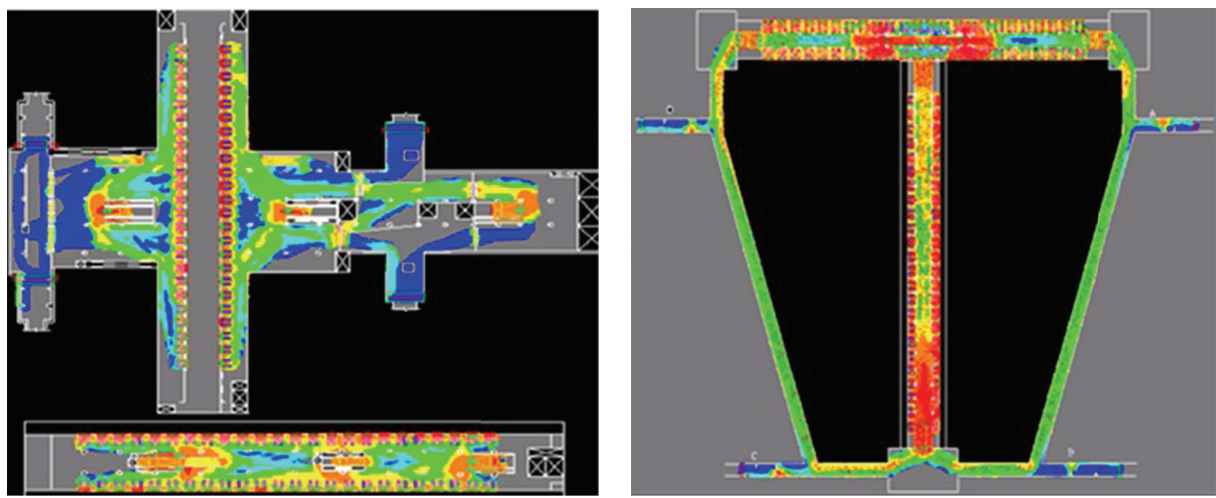

FIGURE 14: Simulated average pedestrian density distribution of HXXJNK and FXM stations (TSCI = 2).

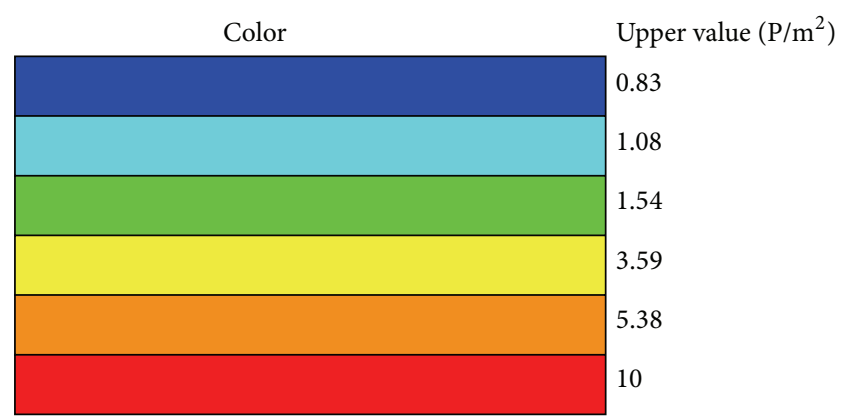

FIGURE 15: Control chart of simulated color and pedestrian density value.

shows that TSCI could reflect the congestion degree of transit transfer stations objectively.

Research findings could act as references for the design and construction of new transit stations, as well as instructions for the improvement of existing ones.

\section{Conflict of Interests}

The authors declare that there is no conflict of interests regarding the publication of this paper.

\section{Acknowledgments}

This work was financially supported by the National Natural Science Foundation of China (no. 51308017), the Beijing Municipal Natural Science Foundation (no. 8122009), Specialized Research Fund for the Doctoral Program of Higher Education (no. 20121103120025), the China Scholarship Council, and the Ministry of Industry and Information Technology of China under the Major Program of National Science and Technology with no. 2013ZX01045003-002.

\section{References}

[1] S. J. Older, Movement of Pedestrians on Footways in Shopping Streets, vol. 10, Traffic Engineering \& Control, London, UK, 1968.

[2] D. Helbing, "A fluid-dynamic model for the movement of pedestrians," Complex Systems, vol. 6, no. 5, pp. 391-415, 1992.

[3] J. J. Fruin, Pedestrian Planning and Design, Metropolitan Association of Urban Designers and Environmental Planners, New York, NY, USA, 1971.

[4] Transportation Research Board: Highway Capacity Manual, National Research Council, Washington, DC, USA, 1994.

[5] P. N. Seneviratne and J. F. Morrall, "Analysis of factors affecting the choice of route of pedestrians," Transportation Planning \& Technology, vol. 10, no. 2, pp. 147-159, 1985. 
[6] Y. Tanaboriboon, S. S. Hwa, and C. H. Chor, "Pedestrian characteristics study in Singapore," Journal of Transportation Engineering, vol. 112, no. 3, pp. 229-235, 1986.

[7] S. P. Hoogendoorn, "Normative pedestrian flow behaviors," LVV rapport, VK 2001.002, Transportation and Traffic Engineering Section, Delft University of Technology, Delft, The Netherlands, 2001.

[8] S. P. Hoogendoorn, "Pedestrian flow modeling by adaptive control," in Proceedings of the 83th Transportation Research Board Annual Meeting, Washington, DC, USA, 2004.

[9] S. P. Hoogendoorn and P. H. L. Bovy, "Normative pedestrian behavior theory and modeling," in Proceedings of the 15th International Symposium on Transportation and Traffic Theory, pp. 219-245, Adelaide, Austral, July 2002.

[10] S. P. Hoogendoorn, "Pedestrian travel behavior in walking areas by subjectiveutility optimization," in Proceedings of the 81th Transportation Research Board Annual Meeting, Washington, DC, USA, January 2002.

[11] K. Kitazawa and M. Batty, "Pedestrian behaivour modelling: an applicationto retail movements using a Genetic Algorithm," in Proceedings of the 7th International Conference on Design \& Decision Support Systems in Architecture and Urban Planning, Eindhoven, the Netherlands, July 2004.

[12] T. Schelhorn, D. O'Sullivan, M. Haklay, and M. ThurstainGoodwin, "STREETS: an agent-basedpedestrianmodel," in Proceedings of the 6th International Conference Computers in urban planning and urban management on the edge of the millenium (CUPUM '99), FrancoAngeli, Venice, Italy, 1999.

[13] J. Desyllas and E. Duxbury, "Planning for movement: measuring and modelling pedestrian flows in cities," in Proceedings of the Royal Institution of Chartered Surveyors (RICS '00) Conference, London, UK, 2000.

[14] Y.-I. Kwon, S. Morichi, and T. Yai, "Analysis of pedestrian behavior and planning guidelines with mixed traffic for narrow urban streets," in Proceedings of the 77th Transportation Research Board, Washington, DC, USA, 1998.

[15] J. Hine, "Pedestrian travel experiences: assessing the impact of traffic on behaviour and perceptions of safety using an in-depth interview technique," Journal of Transport Geography, vol. 4, no. 3, pp. 179-199, 1996.

[16] A. Peter Thompson, Developing new techniques for modeling crowd movement [Ph.D. thesis], University of Edinburgh, Edinburgh, UK, 1994.

[17] P. G. Gipps and B. Marksjö, "A micro-simulation model for pedestrian flows," Mathematics and Computers in Simulation, vol. 27, no. 2-3, pp. 95-105, 1985.

[18] S. P. Hoofendoorn, "Wayfinding under uncertainty in continuous time and space by dynamic programming," in Proceedings of the 13th Mini-EURO Conference, vol. 6, pp. 71-76, 2002. 


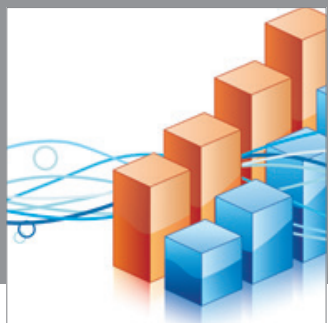

Advances in

Operations Research

mansans

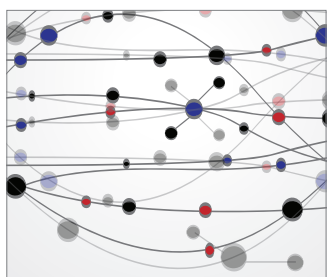

The Scientific World Journal
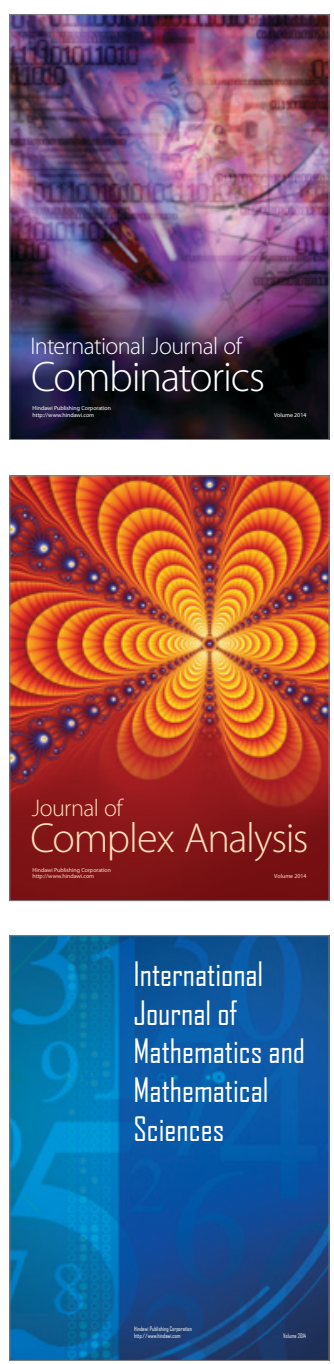
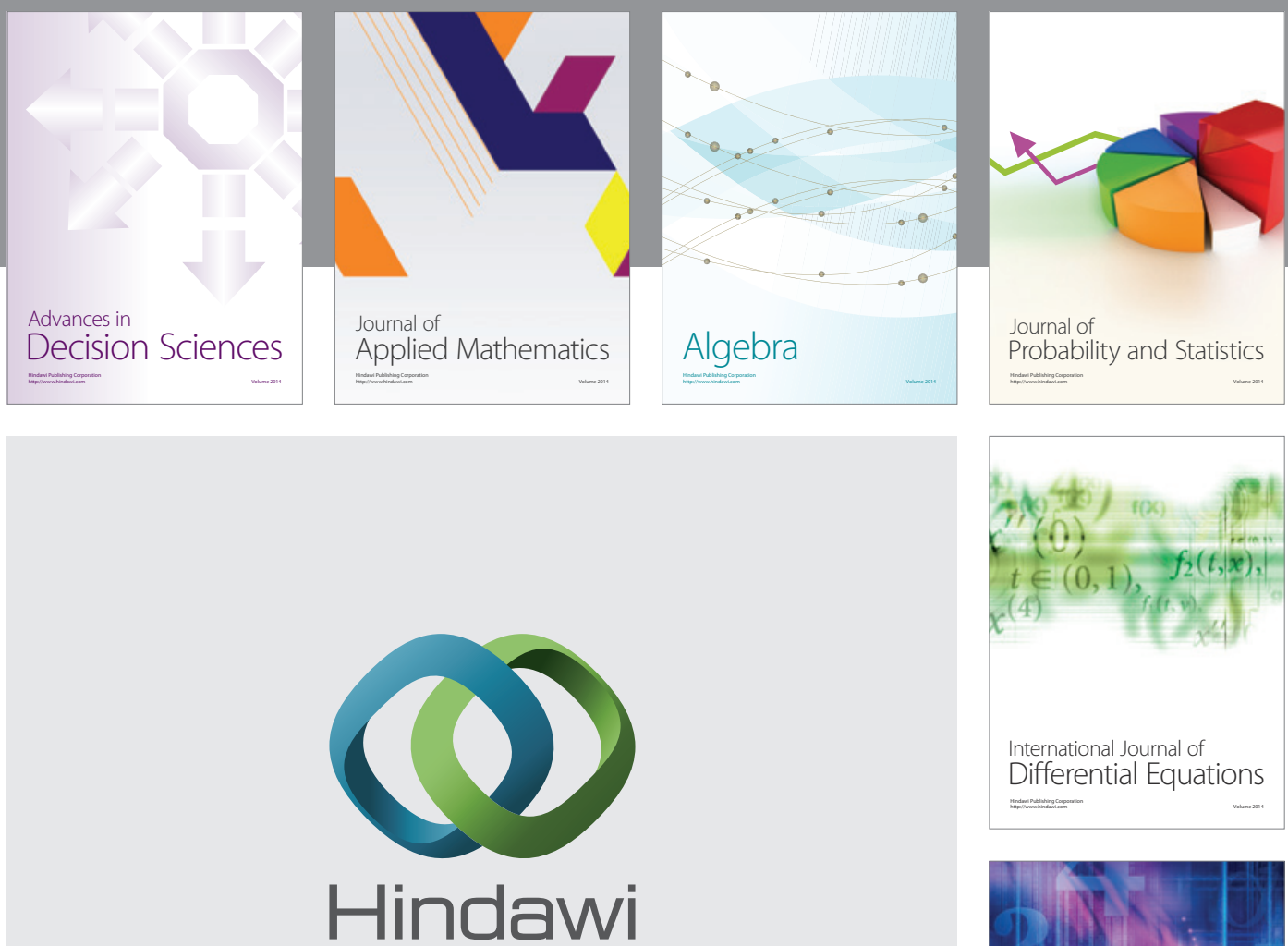

Submit your manuscripts at http://www.hindawi.com
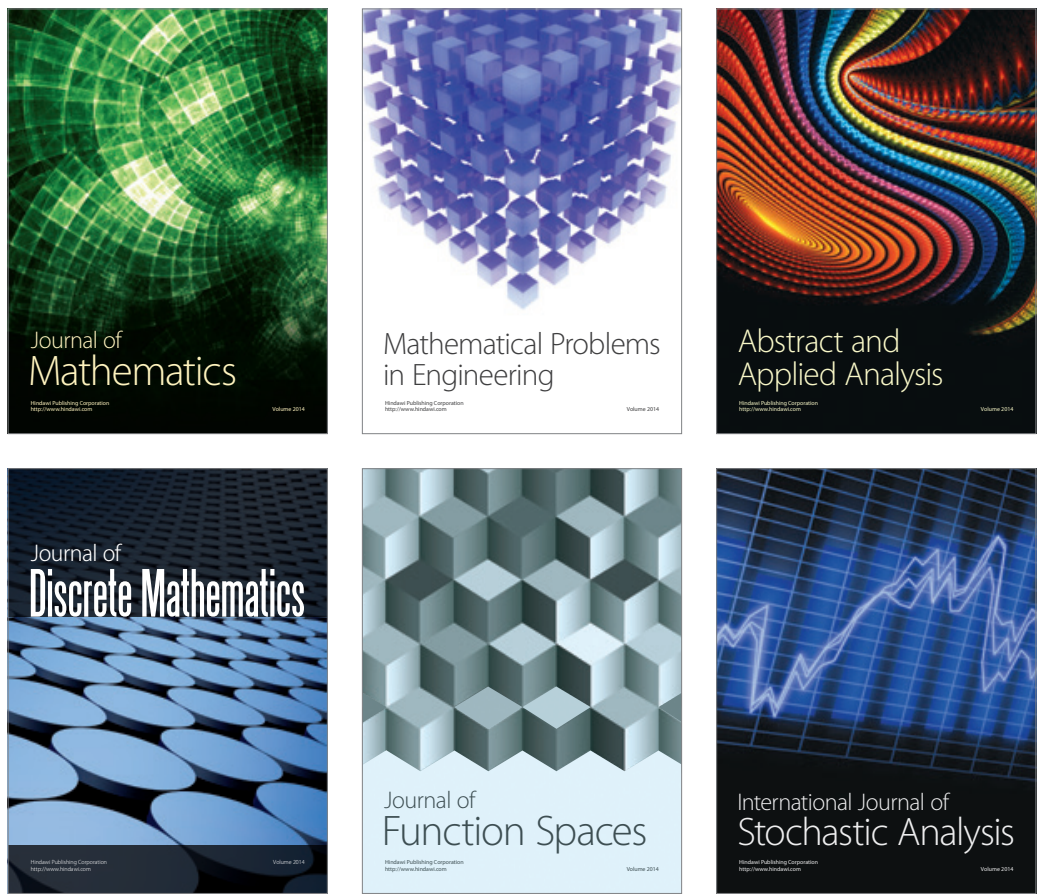

Journal of

Function Spaces

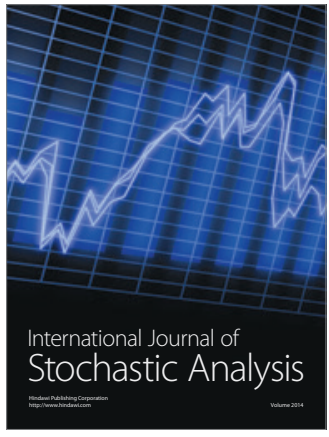

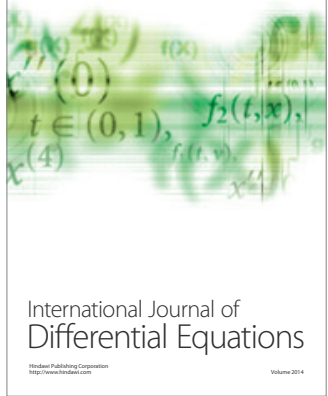
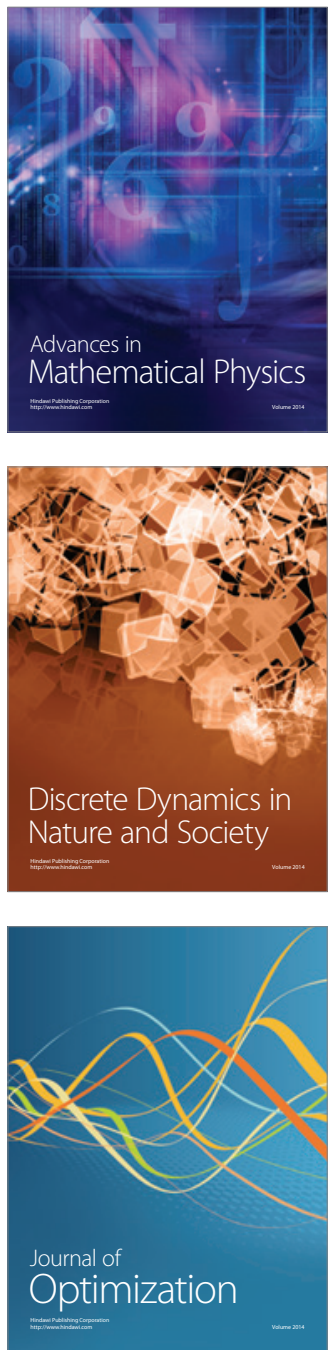